ncome coming into their practices to employ new clinical and administrative staff.

\section{Rewarding results: using financial incentives to improve quality}

\section{Marshall, P Smith}

\section{Financial incentives are soon to be introduced into UK general practice to encourage quality improvement}

$\mathrm{P}$ olicy makers like to experiment with different ways of improving quality. Educational approaches have been dominant in the past. These are usually professionally led and developmental in nature. While they will always play an important role, the evidence that traditional educational methods do not seemtodeliveranacceptablelevelorpaceof change $^{1}$ has come as a surprise to many people. Market based approaches, which rely on the informed consumer or purchaser selectively choosing high quality providers, have also had a disappointing impact on quality. ${ }^{2}$ In part this reflects the lack of real choice and the inadequacy of current sources of data to inform decision making. In a search for an alternative solution, policy makers in some countries have turned to performance management as a lever for change and, more specifically, are examining the use of financial incentives to reward measured performance.

Perhaps the most ambitious and innovative programme to encourage quality improvement is about to be implemented in general practice in the UK. Most British family doctors are not state employees but earn a large proportion of their income from capitation payments under contract with the National Health Service. This rewards general practitioners (GPs) mainly for having a large list of registered patients, but hardly at all for the quality of care that they provide for these patients. GPs were unhappy with their old contract and demanded change. ${ }^{3}$ Protracted negotiations between representatives of the profession and the government have resulted in a new contract ${ }^{4}$ which will be with the practice as a whole, rather than with individual doctors. This contract makes use of specific indictors to reward explicitly those practices providing a high quality of care.

The contract works in the following way. A practice will be awarded points for the level of achievement on each indicator, and these points attract payments. The number of points for each indicator is weighted to reflect the relative importance of that indicator.
There are a total of 136 indicators and a maximum of 1050 points that could be gained by the practice. Seventy six of the indicators, representing $70 \%$ of the total number of points available, relate to clinical care for common primary care conditions such as coronary heart disease, diabetes mellitus, and asthma. Fifty six of the indicators, representing about $18 \%$ of the total points, relate to organisational issues such as infrastructure, staff management, and professional development. Four indicators, representing about $10 \%$ of the total points, relate to patient views of care, assessed using standardised patient experience surveys. The remainder of the points relate to the provision of so called "additional services" such as minor surgery, child health surveillance, and maternity care.

It appears that British GPs are willing to accept the idea of performance related pay; $70 \%$ of family doctors took part in a recent ballot and $79 \%$ of these voted in favour of its implementation in April 2004. Economic theory and evaluations of incentive schemes in other countries give us some insight into the potential impact of the new contract for patients and professionals in the UK. Firstly, we can be confident that practices will respond. Financial incentives have been shown to be an effective way of influencing professional and organisational behaviour in a wide range of countries and health systems..$^{5-7}$ This is particularly true when the incentives are aligned to professional values, targeted on areas that are deemed to be impor$\operatorname{tant}^{8}$ and represent a sufficiently high proportion of total income. ${ }^{9}$ The new GP contract seems to satisfy these criteria. Much of the content addresses areas that clinicians want to improve and the top performing practices have the potential to increase their income by more than one third. Not all of this money will go into doctors' pockets. Some will need to be spent on better systems to improve the delivery of care In addition, individual GPs will be able to choose whether they want to work harder and earn more, or use the new
"It appears that British GPs are willing to accept the idea of performance related pay"

Moreover, there is every chance that within a few years the contract will result in a significant improvement in health outcomes in the UK. General practice is responsible for most of the routine care for the common chronic conditions with a high morbidity and mortality. The clinical indicators in the contract are largely evidence based and it is possible to estimate the health outcome benefits of achieving the level of care determined by the indicators. ${ }^{10}$ These improvements are likely to be secured through changes in the structure of general practice-the contract targets will be more easily attained by large practices with clinical staff specialising in specific disease areas, and by those practices supported by more nurses and administrative staff. ${ }^{11}$

However, alongside these benefits, the incentives are likely to change behaviour in ways that may have a negative impact on the service. ${ }^{12}$ We know that an undue emphasis on external rewards can damage internal professional motivation ${ }^{13}$ and that the level of incentives may have to be maintained or even increased in order to sustain desired performance. Incentives can also focus attention on short term reporting or payment cycles to the detriment of long term strategic planning. We also know that any form of performance management can result in gaming, misrepresentation of data, and sometimes downright fraud. There must be doubts about whether the managerial capacity and data quality in primary care are adequate to monitor and deal with these unintended consequences.

Finally, there are very real concerns that the areas of practice in which it is more difficult to introduce incentives will be downgraded or ignored as primary care teams concentrate their attention on the high priority areasparticularly chronic disease management since this will attract most of the payments. This is less likely to be a problem for the clinical conditions for which there are no incentives; indeed, it is possible that the "halo effect" produced by improved practice systems will result in improvements in all clinical areas. Of greater concern are the more subjective elements which lie at the core of high quality general practice-continuity of care, effective communication, empathy, the promotion of patient 
autonomy, and the coordination and advocacy roles of the family doctor. These patient centred values are generally regarded as the greatest strength of British general practice ${ }^{14}$ and it would be a tragedy if, in an attempt to improve health outcomes, this baby is thrown out with the bath water.

The use of financial incentives to improve performance is not a new phenomenon, but they have never previously been designed in such a sophisticated way nor used on the scale planned in the UK. We do not know whether the very real benefits that will come out of this massive policy experiment will outweigh the risks. In particular, it is unclear whether improvements in population health will come at the expense of patient centred care. There are plans to monitor progress as the contract is implemented and to evaluate its impact on patients and on the service. The results will be awaited with interest.

Qual Saf Health Care 2003;12:397-398

\section{................}

Authors' affiliations

M N Marshall, National Primary Care

Research and Development Centre, University

of Manchester, UK

P Smith, Centre for Health Economics,

University of York, UK

Correspondence to: Professor Martin Marshall, The University of Manchester, National Primary Care Research \& Development Centre, 5th Floor Williamson Building, Oxford Road, Manchester M13 9PL, UK;

martin.marshall@man.ac.uk

The National Primary Care Research and Development Centre and the Centre for Health Economics are both core funded by the UK Department of Health. Professor Smith is funded by ESRC fellowship R000271253. The views expressed in this editorial are those of the authors and not necessarily those of the funding bodies.

\section{REFERENCES}

1 Davis DA, Thomson MA, Oxman AD, et al. Changing physician performance: a systematic review of the effect of continuing medical education strategies. JAMA 1995;274:700-5

2 Marshall MN, Shekelle PG, Davies HT, et al. Public reporting on quality in the United States and the United Kingdom. Health Aff 2003;22:134-48.
3 Smith R. Why are doctors so unhappy? BMJ 2001;322:1073-4.

4 British Medical Association. New GMS contract. London: British Medical Association, 2003.

5 Scott A. Eliciting GPs' preferences for pecuniary and non-pecuniary job characteristics. J Health Econ $2001 ; 20: 329-47$.

6 Robinson J. Theory and practice in the design of physician payment incentives. Milbank $Q$ 1999;79: 149-77.

7 Le Grand J. Knights, knaves or pawns? Human behaviour and social policy. I Social Policy 2002;26: 149-69.

8 Spooner A, Chapple A, Roland M. What makes British general practitioners take part in a quality improvement scheme? J Health Serv Res Policy 2001;6:145-50.

9 Gaynor M, Rebitzer J, Taylor L. Incentives in HMOs. 2001

10 Mant J, Hicks N. Detecting differences in quality of care: the sensitivity of measures of process and outcome in treating acute myocardial infarction. BMJ 1995:311:793-6.

11 Marshall M, Roland M. The new contract: renaissance or requiem for general practice? Br J Gen Pract 2002;52:531-2.

12 Smith P. On the unintended consequences of publishing performance data in the public sector. Int J Public Admin 1995; 18:277-310.

13 Davies HTO, Lampel J. Trust in performance indicators? Qual Health Care 1998;7:159-62.

14 DeMaeseneer J, Hiortdahl P, Starfield B. Fix what's wrong, not what's right, with general practice in Britain. BM 2000;320:1616-7.

\section{A crisis in maternity services: the courage to be wrong}

\section{R Youngson, T Wimbrow, T Stacey}

\section{The response to a crisis experienced in the maternity unit at Waitakere Hospital, New Zealand resulted in profound improvements in care}

W aitakere Hospital in urban West Auckland has a busy maternity unit. Most of our mothers receive care from independent midwives working within the hospital's birthing facilities. Complications during labour are referred to the duty obstetrician. Natural anxiety about coping with emergencies during labour and childbirth is exacerbated by the unit's isolation from other acute services. In 2001 multiprofessional dissatisfaction provoked a breakdown in relationships between obstetricians and midwives.

In some aspects of obstetric care we were not alone. Caesarian section rates in New Zealand between 2001 and 2002 increased from $20.8 \%$ to $22.1 \%{ }^{1}$ but when our caesarian section rate hit $27 \%$ the sense of crisis was ours. Pofessional relationships fractured in a series of "tipping point" events (box l). The symptoms of a breakdown rapidly multiplied: nine major patient complaints in 3 months; enquiry into neonatal deaths; an obstetrician suspended for competency review; and independent midwives refusing to attend hospital policy review meetings at which clinicians questioned midwifery practice. The viability of on call rosters was threatened as morale plummeted and staff resigned.

A way forward with better, safer working practices seemed impossible. It was clear that resolution would only come through a process that focused on interprofessional relationships, however obvious the practical solutions to our problems of poor quality care might seem. A joint letter from 27 independent midwives gave us the opportunity to re-engage, although not before the Minister of Health became embroiled in the dispute. Midwives wrote of serious concerns about their professional autonomy, women's rights, and poor relationship with obstetricians. A series of meetings exposed the high levels of anxiety, anger and blame on all sides. We responded with a process specifically designed to rebuild trust and focus on common goals.

\section{A "DRAMATIC" INTERVENTION}

Known thereafter as the "Big Day Out", a crucial I day workshop led by an outside facilitator was convened, attended by 65 people comprising all the main contributors to obstetric careobstetricians, anaesthetists, paediatricians, midwives, and consumer advocates. To ensure maximum attendance, clinics and routine operating lists were cancelled and locums provided cover for urgent patient care.

The workshop was unusual. Planned but unscripted, it was based on role play. For most, this was an unfamiliar approach to learning and many were fearful. Participants role played labour room crises, slowing down time to allow exploration of interactions, behaviours, beliefs, and difficulties in communication. At first roles were represented by moving furniture. Gradually people volunteered to play their own roles, 


\section{Box 1 A "tipping point" crisis}

- The mother had written an eight page birth plan: no drugs, no machines, no medical interventions; childbirth was to be a mystical and rewarding experience. Progress was slow. The midwife encouraged, supported, and coached the mother through a day and night of painful labour. After an hour of pushing, the exhausted mother began to despair. The midwife was concerned about fetal wellbeing and began continuous monitoring of fetal heart rate. The trace was not reassuring. Experience had taught her that calling the obstetrician would lead to immediate caesarean section. After another half hour of pushing, there was a sudden and prolonged deceleration in fetal heart rate. The obstetrician was called and hurried into the room, followed closely by the anaesthetist. He took one look at the fetal heart rate and told the mother she needed an immediate caesarean. Suddenly there was a rush of frantic activity. The mother burst into tears. Her husband became angry. Consent forms were thrust at the mother and she refused to sign. The midwife and obstetrician exchanged angry words. The obstetrician began to push the bed down the corridor towards theatre while the anaesthetist attempted to complete his pre-anaesthetic evaluation. The mother, nearly hysterical with pain and fear, consented to general anaesthesia and surgery. A healthy baby was delivered. Neither mother nor father witnessed the birth of their child.

then others' roles. At times the tension was electrifying. Some courageously and openly admitted their learning. An independent midwife role playing an obstetrician declared she had never before realised that obstetricians cared about mother and babies as she did, and

\section{Box 2 Working of the} multidisciplinary maternity forum

- Clear ground rules and skilled facilitation created safe learning environments.

- Issues were depersonalised: we focused on behaviour without attacking the person.

- Strong feelings were acknowledged and individual professional needs clarified.

- The wording of issues and resolutions was teased out in a collective process.

- Common goals were identified and respected-improving the care of mothers and babies.

- Through a gradual process of building trust, the voice of consumers was added to the forum and consumer centred solutions developed.

- The priority and strategies for all improvement were governed by the forum, with delegated authority from management. believed that obstetricians just wanted to do operations; she now appreciated the stresses obstetricians experienced. The changed behaviour of doctors was revealing too, but none made such open admission of personal learning.

Few promises were exchanged at that meeting but, crucially, a monthly multidisciplinary maternity forum helped by the same facilitator was agreed and followed. Forum members continued to confront and modify beliefs about others' behaviour and received and acted on feedback about their own. The first forum was characterised by more conflict and heightened emotions. For instance, midwives vehemently defended their right to exclude doctors from the natural process of labour, while hospital specialists railed against lack of preparation of mothers for emergency surgery and anaesthesia. Building enough trust to identify shared goals and create an open learning environment was in the end helped by senior players openly allowing their own reactions to be explored and modified in the role of "vulnerable learner". All of us had "hot buttons" and over reacted to certain issues. Feedback from the facilitator allowed us to recognise our behaviour and explore the often false beliefs underlying our reaction.

Over a 9 month period forum members developed effective ways of working together (box 2) and managed without the facilitator. Eventually this small representative group, exploring often strongly held opposing views, created collaborative solutions that made a difference. An autonomous
Box 3 Conflicting and

interdependent belief systems

- The experience of midwives was that calling an obstetrician into the labour room commonly resulted in immediate caesarean section. The beliefs included:

- The obstetricians don't care about the mother and baby

- They only want to do operations

- They regard the emotional and spiritual aspects of childbirth as unimportant

- If I consult with an obstetrician, he/she will take control and act against the mother's wishes

- The corresponding beliefs of obstetricians and anaesthetists were:

- Midwives are willing to compromise clinical safety for emotional aspects of care

- Midwives give mothers unrealistic expectations about labour

- Mothers are denied helpful interventions such as augmentation of labour

- The doctors are left to deal with all the disasters and may be made accountable for the errors of midwives

quality improvement team was created and driven by the forum. An early success was resolving interprofessional conflict around induction of labour. Independent midwives agreed to allow hospital staff to manage induction so that they could focus on supporting women in established labour. Obstetricians and midwives jointly developed the protocols for the conduct of induction. Consumers in the forum rewrote the patient information leaflet in simpler form. Interprofessional relationships improved and eventually an atmosphere of friendly collaboration replaced the hostility. Morale and staffing levels improved and we currently have no staff vacancies in the maternity unit.

Patients benefited too. Although we never set explicit goals for improvement in clinical outcomes, the gains are striking. The average caesarean rate 
has fallen a third over the last 2 years to $15.3 \%$ compared with the national rate of $22 \%$. Our benchmarked neonatal APGAR scores are now among the best in Australasia (percentage of 5 minute APGAR scores $\leqslant 7$ has fallen from $6 \%$ to $1 \%)$. Patient complaints have reduced in number from an average of nine per quarter to two per quarter.

\section{A HUMAN APPROACH TO LEADERSHIP AND CHANGE}

All of this started 2.5 years ago. Our changes were fuelled by crisis. But what can others learn? Firstly, we would hope that no one experiences such a crisis of care and caring. Nevertheless, our experience suggests that understanding your own and others' views and beliefs, valuing others' contributions, and being open to challenge are as important to quality improvement as the possession of robust data if the aim is to make changes to working practices that lead to significant improvements for patients.

According to the Franklin reality model, life experiences lead to a set of beliefs that determine our personal actions and corresponding results. ${ }^{2}$

Most improvement effort focuses only on the actions required to produce different results. Given the conflicting beliefs of midwives and obstetricians (box 3), we knew that a rational scientific strategy for the reduction of caesarean sections that ignored the underlying beliefs would fail.

Effective leaders focus efforts on creating new experiences that challenge personal beliefs and lead to new behaviours and new results. In adulthood, personal beliefs are relatively fixed and require a significant emotional event to change. In the role play workshop and subsequent forums we intervened in a dramatic way to expose conflicting beliefs and create new shared experience that reinforced common goals and collaborative behaviours. A high risk strategy for all, but particularly for the participants. None of this is for the faint hearted! Courage was required to manage high levels of interpersonal conflict, anger, and blame, but the expression of strong emotion was a necessary part of the process in changing beliefs.

Data alone are not enough. Information demonstrating that some aspects of care for many of our patients was wanting had been available to us for years. But combining data with an honest exchange of views was the key, for the very survival of the maternity unit was at stake. The question for others not at crisis point is how to initiate a climate of trust without having to experience such a crisis first.

We now create our own "crises" by exposing the undiscussable issues and defensive behaviours that are commonplace in any organisation. Currently we are exploring the contradictory world views of geriatricians and acute care physicians. The Franklin reality model is a great place to start. Just ask opposing camps to intuit what personal beliefs underlie the others' observed behaviour and then feed back. Angry reaction? Observe, intuit, and feedback again.

\section{ACKNOWLEDGEMENTS}

The authors acknowledge Don Reekie, Director, Human Development \& Training Institute of $\mathrm{NZ}$, whose remarkable skills in facilitation and sociodrama made this work possible.

Qual Saf Health Care 2003;12:398-400

[.....................

\section{Authors' affiliations}

R Youngson, T Wimbrow, T Stacey,

Waitakere Hospital, Waitemata District Health Board, Auckland, New Zealand

Correspondence to: $\operatorname{Dr} R$ Youngson, Clinical Leader, Waitakere Hospital, Private Bag 93-

115. Henderson, Auckland 1008, New

Zealand, Tel +64 9839 0522, Fax +649 839

0523; E-mail Robin.Youngson@

WaitemataDHB.govt.nz

\section{REFERENCES}

1 New Zealand Health Information Service. Report on Maternity 2001 and 2002. Ministry of Health, Online Publications, 2003 (available at www.moh.govt.nz).

2 Smith H. The Franklin reality model. The Galileo Initiative, 2001 (available at www.galileoinitiative.com).

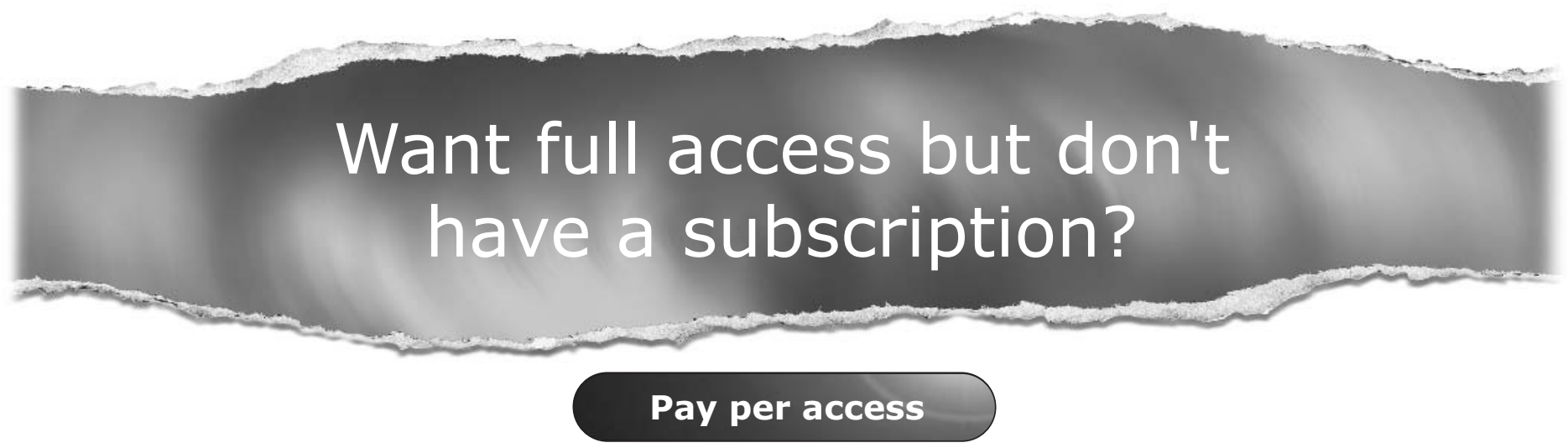

For just US\$25 you can have instant access to the whole website for 30 days. During this time you will be able to access the full text for all issues (including supplements) available. You will also be able to download and print any relevant pdf files for personal use, and take advantage of all the special features Quality and Safety in Health Care online has to offer. 